\title{
О НЕКОТОРЫХ ВОПРОСАХ ИЗУЧЕНИЯ СОВРЕМЕННОГО МУЗЫКАЛЬНОГО ФОЛЬКЛОРА
}

\author{
Арутюнян А. Г., Кандидат искусствоведения, старший научный сотрудник Центра \\ арменоведческих исследований НАН Республики Армения, г. Гюмри, Республика Армения \\ DOI: https://doi.org/10.31435/rsglobal_conf/25112020/7245
}

\begin{abstract}
The modern stage in the development of ethnomusicology is marked by the emergence of large-scale fundamental research. However, the problems of ethnomusicology are essentially not discussed in them, being peripheral for the authors. In this regard, it seems timely to analyze the refraction of ideas and methods of ethnomusicology in the research of scientists - representatives of various regional scientific centers and schools. The lack of interest in the study of modern processes and dynamics of culture is partly due to objective circumstances. Scientists do not always have collections of materials collected in previous periods of the development of science. However, it should be noted that such a trend is characteristic of ethnomusicology, while linguists, for example, are constantly studying and monitoring the transformation of the everyday, scientific language, studying the languages of corporate and information communities, new forms of written culture.
\end{abstract} Keywords: Ethnomusicology, Musical folklore, traditional music, folk song, study, revival.

Музыкальный фольклор - уникальный творческий феномен, в котором сконцентрировано звуковое мышление, ощущение и опыт данного народа. Повторяющиеся, структурированные, часто танцевальные звуки музыки встречаются почти в каждом обществе - наряду с языком. В музыке есть что-то глубоко человечное, но и глубоко культурное, потому что - как и в языках существует множество форм музыки. Однако, в отличие от языка, музыка не требует «понимания». Людей может волновать музыка народов, язык которых для них ничего не значит, и одно и то же музыкальное исполнение может означать разные вещи для разных людей.

Типичная концепция народной музыки 21-го века происходит из представлений о природе музыки и музыкальной жизни деревенских культур Европы с 18 по 19 века, но на эту традиционную народную музыкальную культуру сильно повлиял рост индустриального общества и городов, а также националистические движения, начавшиеся в 19 веке. И угроза народной культуре, и рост национализма стимулировали движения за возрождение и сохранение, в которых образованные музыканты, поэты и ученые обеспечивали лидерство. В 20-м веке дальнейшее возрождение связывало народную музыку с политическими и социальными движениями и стирало музыкальные различия между народной музыкой, искусством и популярной музыкой. Тем не менее, сильные остатки традиционной культуры народной музыки сохранились в Западной Европе 19 века и в Восточной Европе до 20 века; это основы для следующей характеристики.

Местонахождение народной песни редко известно ее сообществу, и поэтому анонимность творческого процесса когда-то считалась основным критерием идентификации народной музыки. Однако стало ясно, что народные песни и другие произведения являются результатом индивидуального творчества либо сельчанами, либо профессиональными или церковными музыкантами, чья работа так или иначе связана с народной культурой. В репертуаре фольклорной общины, вероятно, всегда были песни самого разного происхождения.

"Метод полевого исследования, применяемый в целях реконструкции архаики (обрядов и обрядового фольклора), в настоящее время отнюдь не всегда обеспечивает дальнейшие этапы научной работы полноценным и качественным материалом. Чаще он представляет традицию в редуцированном и фрагментированном виде. Эффективность собирательской работы повышается за счет комплексного целостного охвата объекта - т. е. практически всех компонентов духовной, материальной, соционормативной, жизнеобеспечивающей и других практик. Такой широкий подход в понимании объекта исследования повышает мотивацию деятельности участников экспедиции, вызывает живой интерес к полевому исследованию. Однако, в силу недостаточного объема знаний в смежных областях, изъянов общекультурного уровня отражение этих редуцированных не менее, чем фольклор, форм оказывается таким же неполным, а описания не вполне корректными. Полученный материал находит место в исследованиях, нередко оттесняя собственно музыкальный фольклор. Не отрицая необходимости изучения фольклора в контексте его бытования, по-видимому, следует стремиться к разумному балансу этнографического и 
музыковедческого подходов. Во многом в силу всеохватности не происходит, на наш взгляд, углубления познания закономерностей, имманентно присущих музыкальному фольклору”. [4]

Однако форма народной песни, которую можно услышать в любой момент, скорее всего, сильно повлияла на всю общину из-за ее жизни в устной традиции. Однажды представленная песня могла быть легко исключена из репертуара. Однако более вероятно, что по мере того, как она передается от родителей к детям, друзьям, коллегам и коллегам, она будет изменена. На песню оказали влияние множество факторов, включая творчество, забывчивость, ранее выученные песни и стилистические ожидания. В результате он может стать короче или, например, больше походить на новые стили популярной или церковной музыки. Любая новая песня, скорее всего, подвергнется процессу коллективного воссоздания. Таким образом, важной характеристикой песни или пьесы в традиционной народной культуре является их зависимость от принятия сообществом, то есть деревней, нацией или семьей, а также его тенденция к изменению при передаче от одного человека к другому. и выполнил.

Поскольку народная песня в основном передается в устной форме, она обычно не существует в стандартной форме. В каждом регионе страны, общине, деревне или семье, и даже в репертуаре каждого певца с течением времени могут быть значительные различия. Каждое исполнение песни может быть уникальным. В разговорных обсуждениях народных песен (или сказок) термины «вариант» и «версия» используются, чтобы выделить различия в способах исполнения одной и той же песни (или рассказа одной и той же истории). В технической литературе о фольклоре термины версия, вариант и форма могут использоваться для обозначения степени родства. Так, например, несколько очень похожих исполнений одного певца могут составлять версию песни. Несколько версий, не очень похожих друг на друга, составили бы вариант. Несколько вариантов, включающих совокупность исполнений песни, которые явно связаны, но не однородны, могут быть обозначены как форма.

Кажется, что народные культуры сильно различаются во внутреннем соотношении репертуаров. Например, считается, что английская народная музыка состоит в основном из примерно 40 семейств мелодий, каждая из которых происходит от одной песни. Процесс, с помощью которого члены народных сообществ сочиняют новые песни, не совсем понятен, хотя изучение того, как мелодии связаны между собой, может дать некоторое понимание. Когда она впервые написана, каждая песня - это работа одного композитора; по мере того, как другие учат и поют его, он постоянно воссоздается.

Ключевым в понимании народной культуры является категория традиции. В ходе дискуссии начала 80-х гг. XX в. специалисты пришли к соглашению о понимании ее как механизма отбора и типизации социально-организованного опыта и его трансмиссии. В то же время, имеет место и более широкое понимание этого термина (от лат. traditio - передача) как процесса передачи от поколения к поколению устоявшихся образцов, ценностей, равно как и сами эти образцы и ценности. Осмысление разнообразия традиционных форм культуры в их обусловленности как социальными, так и территориальными факторами привело к корректировке вектора научных исследований, изучению традиции в территориальном развертывании.

"Каковы должны быть методы обработки и использования привлекаемого из архивов полевого материала? Прежде всего, архивные материалы должны подвергаться процедурам текстологического анализа в соответствии с источниковедческим методом, и лишь затем вовлекаться в работу. На это, в частности, указывал Е.В. Гиппиус в исследовании о сборниках М.А. Балакирева и других трудах. Расшифровка, музыкальный анализ, классификация, картографирование должны, по-видимому, выполняться отдельно для каждой однородной по времени коллекции, и лишь затем, при отсутствии серьезных отличий, объединяться в общий массив. В большинстве работ критической оценки источников и текстологического анализа чужих записей нет. В этом смысле положительным примером может служить работа Ю.И. Ковыршиной, использовавшей тысячный массив записей 100-летнего периода, подвергнув его анализу, редактированию (расстановка тактовых черт), а в каких-то случаях новой расшифровке". [4]

Композиционный процесс народной музыки мало отличается от популярной и классической музыки. Например, композитор может создавать новые песни, собирая вместе строки, фразы и музыкальные мотивы из существующих песен, возможно, в сочетании с совершенно новыми песнями и со стандартными формулами открытия или закрытия. Характерные музыкальные структуры, гаммы и ритмы народной музыки также встречаются в других музыкальных стилях той же культуры. Систематическая импровизация как метод композиции встречается лишь изредка, как в эпических песнях. Часто бывает трудно 
установить, создал ли один и тот же композитор и слова, и музыку в народной песне; известно, что многие песни имеют отдельные источники слов и музыки.

Несмотря на свою зависимость от устной традиции, народная музыка, как правило, была тесно связана с музыкой в письменной традиции, и эта связь усиливалась в периоды урбанизации и возрождения. Многие народные песни возникли в письменной форме. На протяжении многих веков популярные и классические композиторы адаптировали народную музыку и, в свою очередь, оказали влияние на устную традицию. Современный аналог письменной традиции, звукозапись, существенно повлиял на устную традицию, поскольку народные певцы могли слышать различные аранжировки народной музыки в частных и коммерческих записях. Таким образом, передача народной музыки не была изолированным процессом, а переплетена с другими видами передачи музыки.

Мелодии часто мигрируют между соседними странами. Несколько типов мелодий можно найти повсюду в ареале европейской культуры, а текстовые типы (например, балладные рассказы) распространены более широко, чем типы мелодий. Однако каждая страна имеет свой репертуар со стилистическими особенностями, а также мелодиями, которые не используются соседями.

Традиционное сельское общество вело активную музыкальную жизнь, в которой многие песни в большинстве жанров были известны и часто исполнялись значительной частью населения. Тем не менее, определенная степень музыкального профессионализма должна быть получена; инструменталисты, хотя и не имели формального образования, были специалистами, как и певцы эпических повествований и певцы профессиональных песен. Западные культуры обычно исповедуют одни и те же жанры народной музыки. Одна из самых важных - баллада, обычно короткая повествовательная песня с повторяющимися строками.

Эпосы - это более длинные повествования в героическом стиле, на исполнение которых иногда требуется много часов. Некоторые песни носят церемониальный характер и предназначены для сопровождения событий в жизненном цикле человека или в год сообщества (например, связанные с сельскохозяйственными сезонами). Другими распространенными жанрами являются рабочие песни, песни о любви и другие лирические песни, песни для игр, колыбельные и детские песни для инкультурации (например, песни с алфавитом, пословицы и загадки). Эти жанры обычно различаются по текстам, но в некоторых культурах также есть различия в музыке. Инструментальная народная музыка чаще всего сопровождает танец.

Поскольку народная музыка живет в устной традиции, ее историю лучше всего понять, изучив ее связь с другими музыкальными произведениями. Многие народные песни, собранные в устной традиции, восходят к литературным источникам, зачастую весьма древним. В средневековой Европе с распространением христианства были предприняты попытки подавить народную музыку из-за ее связи с языческими обрядами и обычаями; тем не менее, некоторые аспекты европейской народной музыки были ассимилированы в средневековую христианскую литургическую музыку, и наоборот. Народная музыка также сознательно включалась в европейские музыкальные произведения искусства на протяжении всей истории, особенно в периоды обновления, начиная с эпохи Возрождения.

“Современный этап развития этномузыкологии ознаменован появлением масштабных фундаментальных исследований. Однако проблемы этномузыкологии в них по существу не обсуждаются, являясь для авторов периферийными. В связи с этим представляется своевременным анализ преломления идей и методов этномузыкологии в исследованиях ученых - представителей разных региональных научных центров и школ. Отсутствие интереса к изучению современных процессов и динамики культуры отчасти обусловливается объективными обстоятельствами. Далеко не всегда ученые располагают коллекциями материалов, собранными в предшествующие периоды развития науки. Однако нельзя не отметить, что подобная тенденция характерна именно для этномузыкологии, в то время как лингвисты, например, постоянно занимаются изучением, и мониторингом трансформации бытового, научного языка, изучают языки корпоративных и информационных сообществ, новые формы письменной культуры”. [4]

\section{ЛИТЕРАТУРА}

1. Алексеев Э. Е. Фольклор в контексте современной культуры: рассуждения о судьбах народной песни. - М.: Советский композитор, 1988.

2. џиевич Ю. Е. Словарь музыкальных терминов. - К.: Музычна Украйина, 1988

3. Яных E.A. Словарь музыкальных терминов. - М.: АСТ, 2009.

4. Рудиченко Т.С. ПРОБЛЕМЫ МЕТОДОЛОГИИ СОВРЕМЕННОЙ ЭТНОМУЗЫКОЛОГИИ // Фундаментальные исследования. - 2014. - № 12-11. - С. 2487-2490. 